\title{
DYNAMICS OF THE FKT SYSTEM WITH DIFFERENT MOORING LINES
}

\author{
Jo-Ti Wu ${ }^{1}$ \\ Jiahn-Horng Chen ${ }^{1}$ \\ Ching-Yeh Hsin ${ }^{1}$ \\ Forng-Chen Chiu ${ }^{2}$ \\ ${ }^{1}$ National Taiwan Ocean University, Keelung, Taiwan \\ ${ }^{2}$ National Taiwan University, Taipei, Taiwan
}

\begin{abstract}
To harness the endless hydrokinetic energy of the Kuroshio current, the joint research team of the National Taiwan University and the National Taiwan Ocean University has developed a floating Kuroshio turbine (FKT) system in Taiwan. In normal operation, the system floats at a certain small depth from the ocean surface to reduce the wave effects and take advantage of faster current speeds. In the present study, the effect of the mooring line on the system dynamics is investigated computationally. Two different auxiliary mooring line designs and, for each design, three different common mooring lines (polyester ropes of neutral buoyancy, iron chains, and $6 \times 19$ wires ropes with wire core) are examined. The study makes use of several commercial and in-house packages, integrated to find various coefficients. It is found that the mooring line, the auxiliary mooring line design, and the gravity centre can have a significant effect on system fluctuations in normal operation if the combination of these factors is not properly matched.
\end{abstract}

Keywords: ocean current energy; floating turbine system; mooring line; system dynamics; surface waves

\section{INTRODUCTION}

The greenhouse gas emission due to excess use of fossil fuels has resulted in serious global warming and disastrous climate change. Scientists around the world warn that the likelihood of extreme heat, dryness and precipitation will keep increasing globally [1]. Driven by the need to control the climate change, the development of renewable energy utilisation has become a new technological frontier. Among various possible renewables, marine energy with its abundance in resources and huge power potential can become an important source. The technologies to harness marine energy are far from maturity at present. Many challenges have been addressed in the literature [2]. Coping with these challenges, various devices were devised for harnessing different kinds of marine energy in the past several decades. Among them are the ocean current turbine systems which, in fact, represent another level of deep-water renewable energy technology. With the advancement of technology, several prototypes of ocean energy devices have been developed, e.g. [3-8].
One of the key issues in harnessing ocean current energy is the deep-sea mooring system which connects the current turbine floating in the ocean current and the anchor of some kind fixed on the sea bed. This was a new research topic in the past decade. The interdependency between the mooring and ocean current turbine systems plays a crucial role early in the design phase. Numerous studies have been conducted, but each of them was mostly limited to a particular type of ocean current turbine and mooring system.

Cribbs [9] has developed a numerical procedure to model the mooring system for the $20-\mathrm{kW}$ current turbine system proposed by a research team at the Center for Ocean Energy Technology, Florida Atlantic University. He attempted to optimize the mooring attachment locations on the floating body, the tether arrangement, and the locations of two floating devices attached to the mooring line. Cribbs and Van Zwieten [10] have also studied in detail the sensitivity of system responses to parametric variations. Shibata et al. [11] have conducted both experimental and numerical studies to investigate the stability of a $\mathrm{V}$-shape mooring system 
connected to an ocean turbine developed by Takagi et al. [12]. Rho et al. [13] have proposed methods to select and optimize the mooring system for a tidal turbine located in a shallow water region. They concluded that the SPAR type has better performance for a multi-arrayed system. More recently, Tsao and Feng [14] have developed the cross-stream active mooring system to adjust the horizontal position of a current turbine in order to track fast streams and thus increase the power generation capacity.

Waves are a source of system instability for a moored ocean current turbine system. The wave-turbine interaction is an important issue in developing the floating current turbine systems. Shirasawa et al. [15] have tested the system dynamics of the ocean current turbine with a single mooring line under the action of waves. Although the ocean current turbine works at the middle layer of the water flow, the wave influence is significant. They pointed out that when the wave length is long, compared to the turbine operation depth, selecting a proper mooring method is important for making the deployment stable. Wu et al. [16] have investigated the effect of mooring line design and waves on the dynamics of the current turbine system developed by the research team of the National Taiwan University and the National Taiwan Ocean University. Their results show that the surface waves induce pitching oscillation of the system which becomes significant when the wave propagation is parallel to the current flow and its period is close to the system resonant period.

Recently, Cribbs et al. [17] have surveyed the existing mooring standards. They pointed out that modelling mooring dynamics can be complicated and the loads and fatigue cycles of a mooring system can easily be underestimated due to unexpected marine environments. It implies that more studies are indispensable to understand fully the interaction between the mooring and the current turbine system in a very dynamic ocean environment. Finally, it is worth mentioning that some studies were also conducted for mooring systems applied to tidal stream current turbines. Bowie [18] argued that a flexible mooring system offers advantages for tidal current turbines in installation and maintenance. Jo et al. [19] have also investigated the mooring system with a duct-type tidal current turbine system in shallow water.

\section{FKT SYSTEM}

To harness the endless hydrokinetic energy brought by the Kuroshio current passing Taiwan's east coast from south to north, the floating Kuroshio Turbine (FKT) was designed by the joint team of the National Taiwan University and the National Taiwan Ocean University. Fig. 1 shows a floating device moored to the seabed with an anchor and mooring line system. The rated power of the system is $0.5 \mathrm{MW}$ at the current speed of $1.5 \mathrm{~m} / \mathrm{sec}$. The system comprises five major components. The uppermost part is the foil float, equipped with two aft- and two fore-buoyancy engines. The float provides buoyancy for the system. It also serves to provide proper dynamic lift helping the system float or dive more readily. This is accomplished by flooding or draining water out of some of these buoyancy engines to create positive or negative incident angle of the incoming flow to the foil float. Two vertical supports connect the foil float and the current turbine system which consists of two rotors. The turbines are connected by a flat-plate cross beam. The turbines harness the ocean current energy, and electricity is generated by the direct-drive permanent-magnet generator set inside the turbine nacelles.

The FKT project is at the stage of feasibility study. For this purpose, a 1/5 model has been adopted for investigation. The chord length is $4.0 \mathrm{~m}$, the span is $7.5 \mathrm{~m}$, and the rated power is $20 \mathrm{~kW}$ at the current speed of $1.5 \mathrm{~m} / \mathrm{sec}$. The water depth is specified to be $50 \mathrm{~m}$. The design operating depth is $10-40 \mathrm{~m}$. A single-line mooring system is provided. Two different short auxiliary mooring line systems: 2-AML and 3-AML, were investigated. The 2-AML system consists only of two side lines, as shown in Fig. 1. These lines connect the trailing points of the nacelles and the main line. The 3-AML system has three lines, with the same two side lines as in the first system and an additional one connected to the midpoint of the cross beam. In each system, the auxiliary lines join together the connector with the main line which is then connected to the anchor on the seabed. It was assumed that all lines can freely slide on the connector. The length of the main line is $40 \mathrm{~m}$. Each of the auxiliary side lines is $5 \mathrm{~m}$ long, while the length of the middle line is $3.8 \mathrm{~m}$. To make the system horizontal when it operates under normal conditions, the centres of gravity for the two systems are different. For the 2-AML, the centre is $2.12 \mathrm{~m}$ downstream of the trailing point of the nacelle, while for the 3-AML it is $1.69 \mathrm{~m}$. The centre of buoyancy, the same for the two designs, is $1.85 \mathrm{~m}$ downstream of the trailing point of the nacelle. The system weight is 15.262 tones when the buoyancy engines are empty and 19.722 tones when they are full of water.

\section{METHOD OF STUDY}

The system dynamics was investigated computationally. There are several forces acting on the FKT system. They include buoyancy (mainly from the foil float), weight, hydrodynamic drag when the current passes the system and the mooring lines, dynamic lift due to the foil float, tension forces exerted by the mooring lines, and the propulsive force produced by the contra-rotating turbines.

The system buoyancy and weight were obtained directly from the system design data. The buoyancy is related to the volume of the system which is also available from the design data. The turbine blades were designed using the in-house lifting line and the lifting surface code. The foil float of finite span provides the dynamic lift. The lift coefficient was taken from [20] with the aspect ratio $A R=2$.

The system drag coefficients were found by using the commercial software FLUENT. The computations were based on the Reynolds-averaged Navier-Stokes equations, which were solved with the standard k- $\varepsilon$ turbulence model. The standard wall function was adopted for the flow near the solid wall. The SIMPLE algorithm was employed for nonlinear 
iterations between the velocity and pressure fields. It was assumed that the current has a uniform speed of $1.5 \mathrm{~m} / \mathrm{sec}$.

We define the drag coefficients

$$
\mathrm{C}_{d}=\frac{D}{\frac{1}{2} \rho U^{2} A}
$$

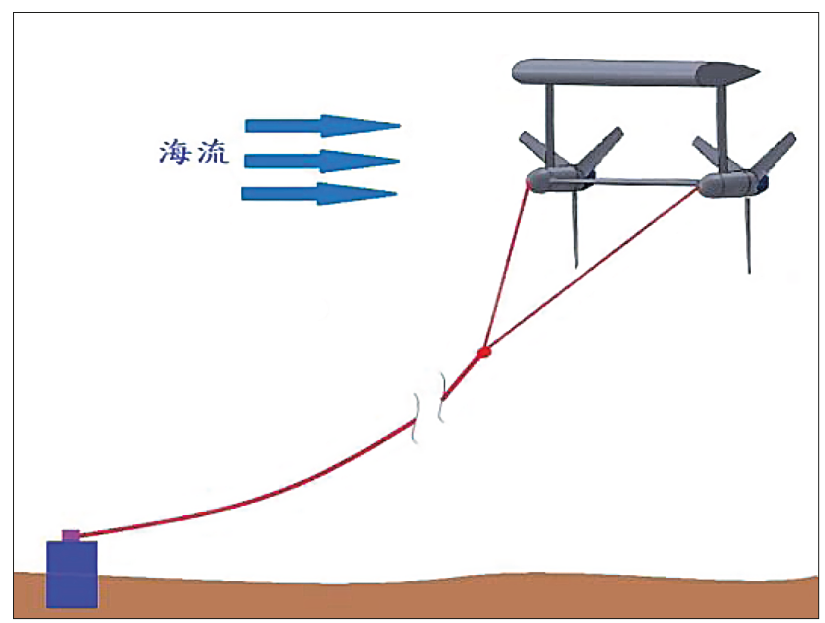

Fig. 1. Schematic of the FKT system

Tab. 1. Drag coefficients for linear and angular motions

\begin{tabular}{|c|c|c|}
\hline \multicolumn{3}{|c|}{ Linear motion } \\
\hline$\left(C_{d}\right)_{x}$ & $\left(C_{d}\right)_{y}$ & $\left(C_{d}\right)_{z}$ \\
\hline 0.173 & 1.184 & 1.318 \\
\hline \multicolumn{3}{|c|}{ Angular motion } \\
\hline$\left(C_{d}\right)_{x \text {-axis }}$ & $\left(C_{d}\right)_{y \text {-axis }}$ & $\left(C_{d}\right)_{z \text {-axis }}$ \\
\hline 0.364 & 0.228 & 0.012 \\
\hline
\end{tabular}

Tab. 2. Added mass coefficients for linear and angular motions

\begin{tabular}{|c|c|c|}
\hline \multicolumn{3}{|c|}{ Linear motion } \\
\hline$\left(C_{a}\right)_{x}$ & $\left(C_{a}\right)_{y}$ & $\left(C_{a}\right)_{z}$ \\
\hline 0.173 & 0.369 & 4.15 \\
\hline \multicolumn{3}{|c|}{ Angular motion } \\
\hline$\left(C_{d}\right)_{x \text {-xis }}$ & $\left(C_{d}\right)_{y \text {-xis }}$ & $\left(C_{d}\right)_{z \text {-axis }}$ \\
\hline 18.2 & 4.16 & 1.23 \\
\hline
\end{tabular}

and

$$
\left(\mathrm{C}_{d}\right)_{M}=\frac{M}{\frac{1}{2} \rho \omega^{2} A_{M}}
$$

for linear and angular motions, respectively. Their exact values obtained by Lo [21] for the 6 degrees of freedom are given in Table 1. In Eqs. (1) and (2), $D$ is the drag, $\rho$ is the fluid density, $U$ is the uniform incoming current speed, $A$ is the projected area of the system in the flow direction, $M$ is the angular drag, $\omega$ is the angular velocity, and $A_{M}$ is the area moment of inertia corresponding to the axis about which the outer flow rotates.
Moreover, we define the added mass coefficients for the linear and angular motions, respectively:

$$
\begin{gathered}
C_{a}=\frac{m_{a}}{\Delta} \\
C_{a}=\frac{I_{a}}{\Delta \times l_{c}^{2}}
\end{gathered}
$$

and

Their values can be obtained via the commercial code WAMIT, which employs the boundary element method in computations. In Eqs. (3) and (4), $m_{a}$ is the added mass, $\Delta$ is the displacement of the system, $I_{a}$ is the added moment of inertia, and $l$ is the characteristic length corresponding to the rotating axis. The product $\Delta \times l_{c}^{2}$ represents the hydrodynamic moment of inertia about the centre of gravity. Table 2 shows the coefficients obtained by Lo [21].

The mooring line can be modelled with a catenary line. With all the coefficients obtained as described above, the system dynamics was analysed by employing the commercial package OrcaFlex. This is a time-domain FEM code widely used in offshore industry. To integrate in time, the implicit generalized- $\alpha$ method was selected which damps numerical oscillations with high-frequency dissipations. Moreover, the FKT system was simplified as lumped mass element.

\section{RESULTS: 2-AML SYSTEM WITHOUT SURFACE WAVES}

In this section, the deployment system dynamics of the FKT during deployment is studied computationally. Three kinds of mooring lines, i.e., polyester ropes, iron chains, and $6 \times 19$ wire with wire core, are considered.

\section{A. Polyester ropes}

Three cases were studied in which the rope diameters were $d=0.03 \mathrm{~m}, 0.1 \mathrm{~m}$, and $0.3 \mathrm{~m}$, respectively. All mooring lines were identical in material and neutrally buoyant. It was assumed in the computations that the bulk modulus is infinite, the axial stiffness is $700 \mathrm{kN}$, the bending stiffness is $120 \mathrm{kN} \mathrm{m}^{2}$, the torsional stiffness is $80 \mathrm{kN} \times \mathrm{m}^{2}$, and the Poisson ratio is 0.5 . The mass per unit length is $0.707 \mathrm{~kg} / \mathrm{m}$, $7.854 \mathrm{~kg} / \mathrm{m}$, and $70.68 \mathrm{~kg} / \mathrm{m}$ for $d=0.03 \mathrm{~m}, 0.1 \mathrm{~m}$, and $0.3 \mathrm{~m}$, respectively.

The dynamic responses of the system for $d=0.03 \mathrm{~m}$ are shown in Fig. 2. No waves are present in this case. It is interesting to see in Figs. 2(a) and (b) that the system appears stable during the flooding process. However, when the turbines start to operate, the FKT system suffers serious pitching and rolling motions, the amplitude of which is quickly amplified.

The results for $d=0.1 \mathrm{~m}$ are shown in Fig. 3. Similar system fluctuation phenomena can be found here. The pitching motion results in dynamic lift fluctuations of the foil float and induces system heaving motions. Even though the diameter is larger, the amplitude of temporal fluctuation is almost as big as that for $d=0.03 \mathrm{~m}$. However, the pitching growth rate is slightly smaller, and it takes a longer time for the pitching motion to develop. 


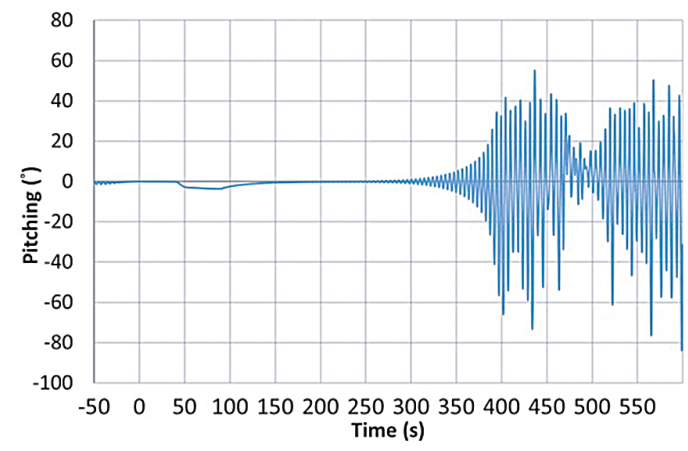

(a) Time-history of system pitching motion

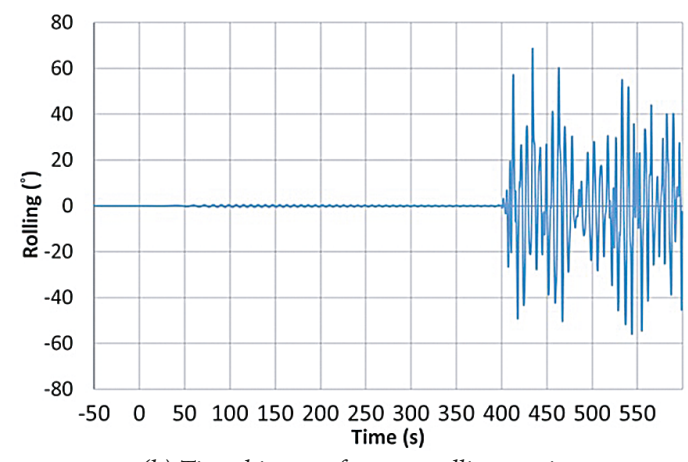

(b) Time-history of system rolling motion

Fig. 2. System dynamics results for $d=0.03 \mathrm{~m}$

Fig. 4 shows the results for $d=0.3 \mathrm{~m}$. Only the heaving motion is shown here because the deployment is fully stable. No pitching and rolling motions have been incurred. The diameter of the mooring line has a significant effect on the system dynamics during deployment. Obviously, it should be large enough to make the system stable during the deployment process.

\section{B. Chains}

Fig. 5 shows the geometry of the employed chains. Three different nominal diameters were selected: $d=0.03,0.04$, and $0.05 \mathrm{~m}$. The mass per unit length is $21.9 d^{2}$ te $/ \mathrm{m}$, the axial stiffness is $1.01 \times 108 d^{2} \mathrm{kN}$, and the bending stiffness is 0 . The normal and axial drag coefficients are 2.6 and 1.4, while the normal and axial added mass coefficients are 1.0 and 1.4, respectively.

Fig. 6 shows the results of the system heaving motion during the deployment process. For all cases, the motion is stable, and the system reaches its final operating position smoothly. Compared to the case with flexible ropes, the iron chain can obviously lead to safer and much more satisfactory deployment. It is also evident that the chain with a larger nominal diameter is heavier per unit length and, therefore, the FKT system sinks to a deeper position under normal operating conditions.

\section{C. $6 \times 19$ wire rope with wire core}

Wires have many applications in the offshore industry including towing, mooring and winching. Fig. 7 shows the $6 \times 19$ wire rope with wire core which was used in the present study. We assumed the Young's modulus to be $1.13 \times 108 \mathrm{kN} / \mathrm{m}^{2}$ and the axial stiffness to be $4.04 \times 10^{7} d^{2} \mathrm{kN}$.

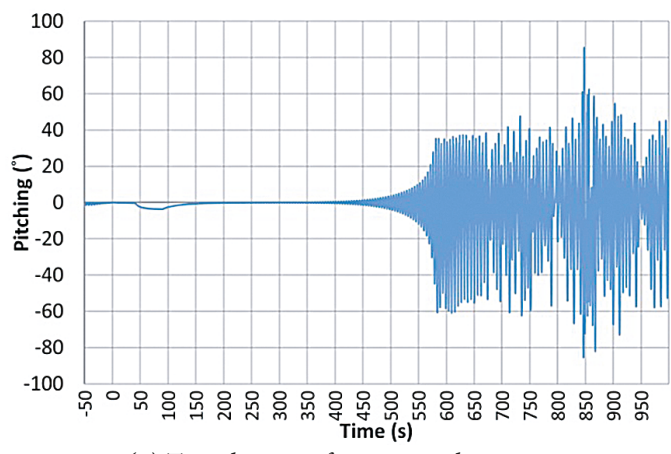

(a) Time-history of system pitching motion

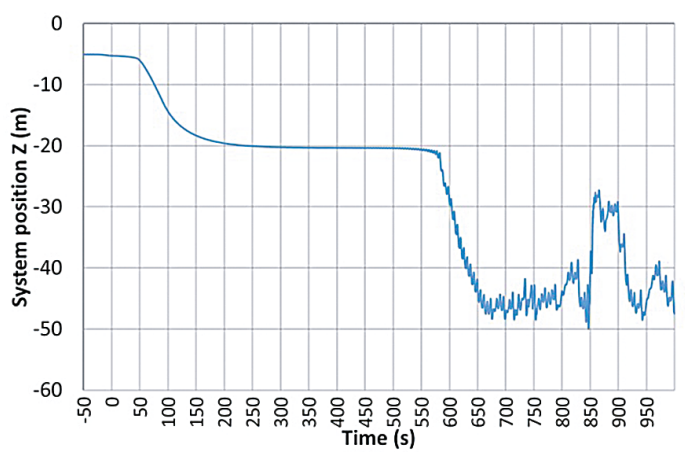

(b) Time-history of system heaving motion

Fig. 3. System dynamics results for $d=0.1 \mathrm{~m}$

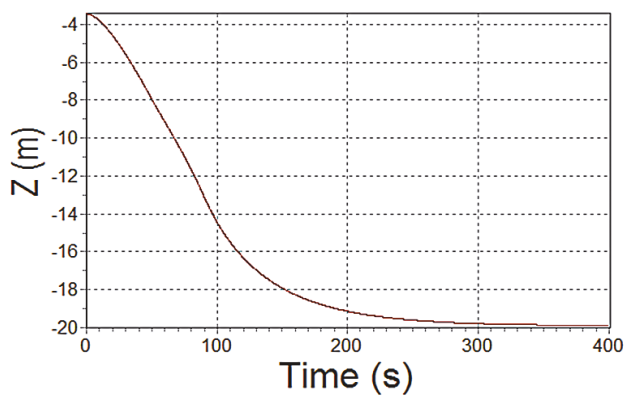

Fig. 4. Time-history of system heaving motion for $d=0.3 \mathrm{~m}$ $d=$ Nominal Diameter

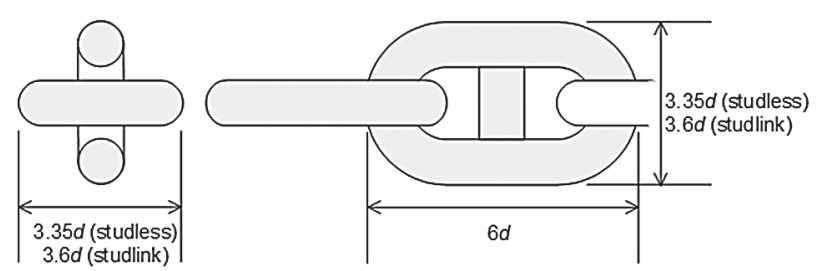

Fig. 5. Geometry of chains used in the study [22]

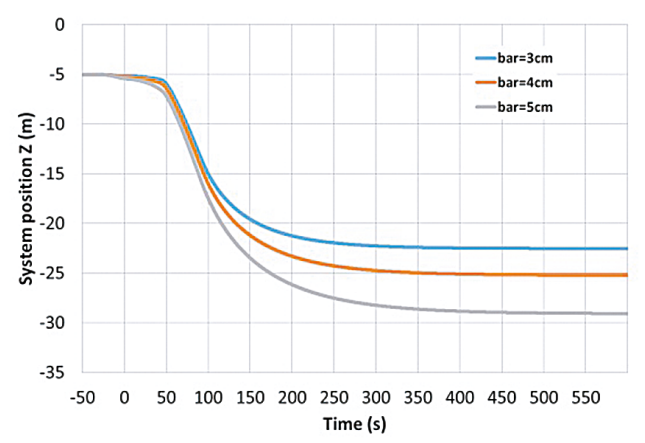

Fig. 6. Heaving motion of system with iron chains of different diameters 


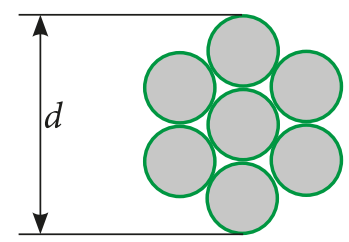

Fig. 7. $6 \times 19$ wire rope with wire core [22]

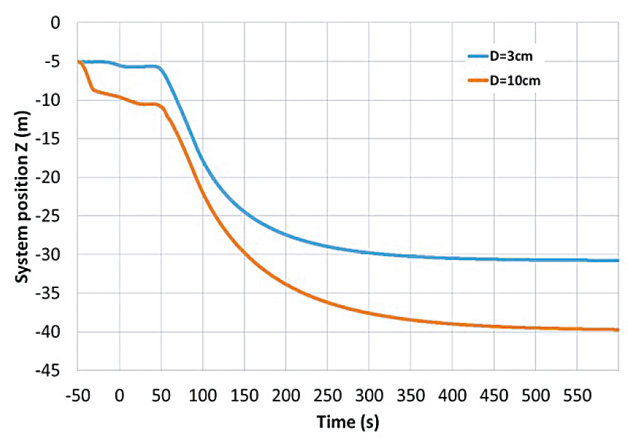

Fig. 8. Heaving motion of system with wire ropes of different diameters

Furthermore, we also assumed that the metallic area is 0.455 $\left(\pi d^{2} / 4\right)$, where $d$ is the nominal diameter of the wire rope as shown in Fig. 7. For simplicity, the bending stiffness was assumed zero. In this investigation, two different values of $d: 0.03$ and $0.1 \mathrm{~m}$ were examined.

The results are shown in Fig. 8. They are similar to those shown in Fig. 6 for chains. In fact, the wire rope is even heavier. Hence, it can be expected that the deployment would be smooth. Again, there are no fluctuation motions in all six degrees of freedom of the system. Furthermore, the system operates at an even larger depth from the free surface when it settles. It is also interesting to note that during the deployment, it takes about the same time for the system to reach its stable operating position if the deployment incurs no instability. This can be observed in Figs. 4, 6, and 8.

The study seems to imply that for a smooth deployment, the mooring line should be relatively heavy (in terms of its linear mass density). There exists a critical value of the linear mass density which ensures the system to be deployed stably. In fact, a chain of the same shape as the iron one but of neutral buoyance was also investigated, and the results have shown that the system deployment is unstable. Therefore, the material of the mooring line may be considered of no importance, while the only important factor is its linear mass density.

\section{RESULTS: 2-AML SYSTEM WITH SURFACE WAVES}

The next studied case represents a more complicated deployment process due to the presence of waves. In fact, this case better reflects a real sea deployment. The wave height was assumed to be $1 \mathrm{~m}$. Since the deployment for the system with flexible ropes is usually not stable in a calm sea if the line diameter is not sufficiently large, only the mooring systems with iron chains and wire rope in waves were analysed. Generally, our study shows that the pitching motion is the most important factor which may cause instability or fluctuations in the system. Hence, the following discussion will focus on system pitching motion only. Before proceeding to the discussion, it should be first mentioned that the system has a natural period of about $5 \mathrm{sec}$ in pitching motion [21], which has been verified by Wu et al. [23].

\section{A. Chains}

The wave period is a critical parameter which may affect system dynamics. Another parameter which also interacts with the system motion is the wave direction. In the following discussion it is assumed that the incoming wave moves in the opposite direction as that of the current. This is the most critical wave direction, as in the Taiwan area the winter monsoon consistently creates big waves for a few months. The waves also reduce the flow speed of the Kuroshio current in winter.

The pitching motions for $d=0.03 \mathrm{~m}$ and different wave periods, $T$, are shown in Fig. 9. If the period is small, $T=4$ $\mathrm{sec}$, the system reaches its stable operation quickly, as shown in Fig. 9(a). However, for $T=5 \mathrm{sec}$, the system suffers from serious periodic pitching motion. Even at $T=6 \mathrm{sec}$, the pitching fluctuation is still significant.

A slightly different pattern is shown in Fig. 10 for $d=0.04 \mathrm{~m}$. At $T=4 \mathrm{sec}$ and $6 \mathrm{sec}$, the long-term behaviour of pitch motion is similar to that when $d=0.03 \mathrm{~m}$. However, at $\mathrm{T}=5 \mathrm{sec}$, the pitching fluctuation is much reduced.

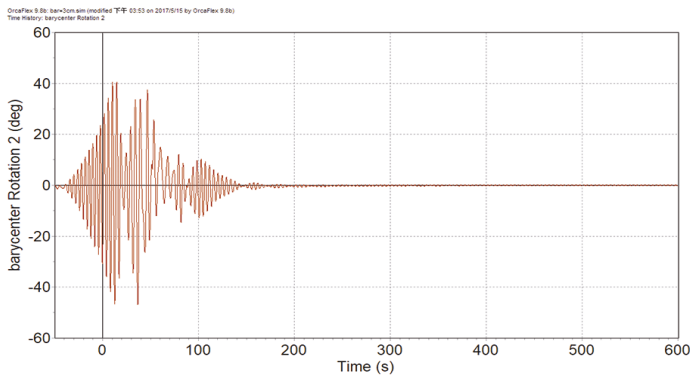

(a) $T=4 \mathrm{sec}$

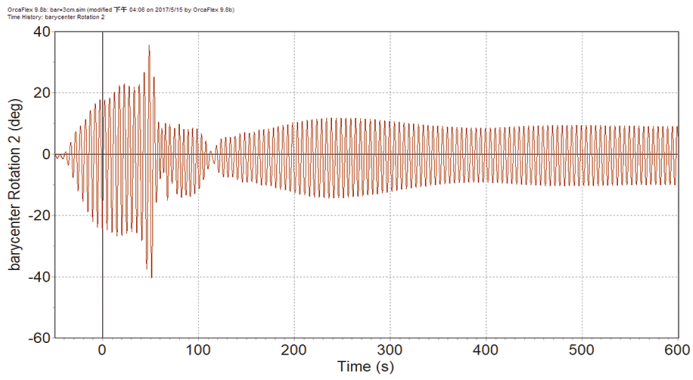

(b) $T=5 \mathrm{sec}$

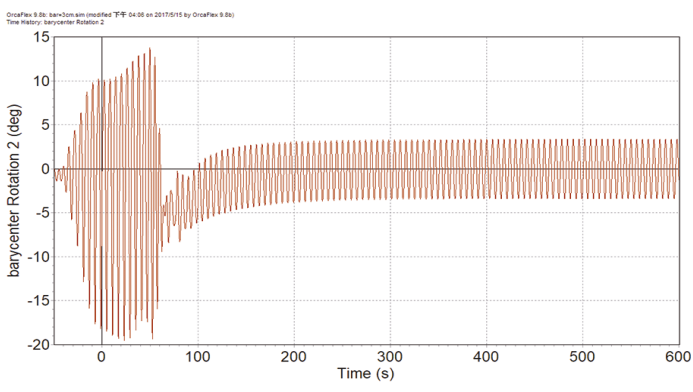

(c) $T=6 \mathrm{sec}$

Fig. 9. Pitch motion of system with iron chain of $d=0.03 \mathrm{~m}$ 


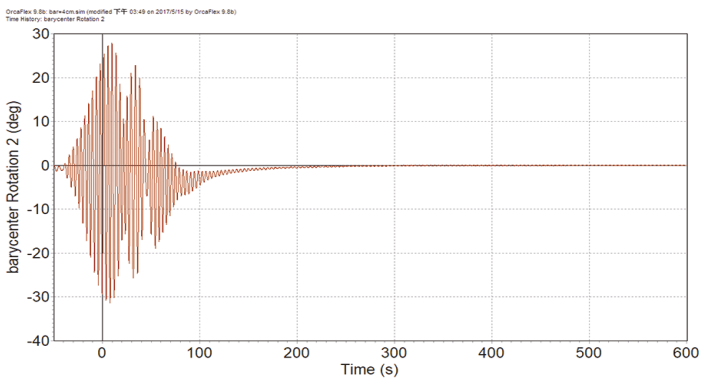

(a) $T=4 \mathrm{sec}$

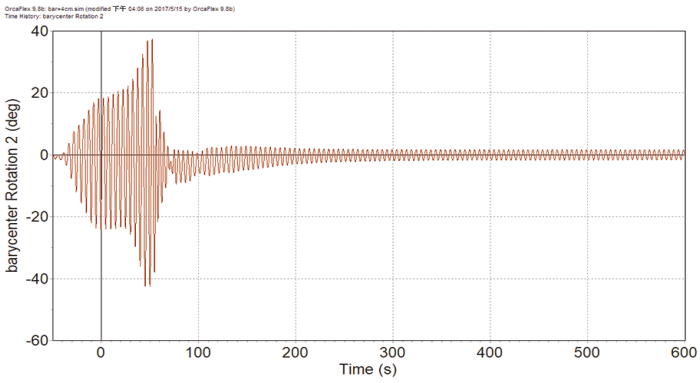

(b) $T=5 \mathrm{sec}$

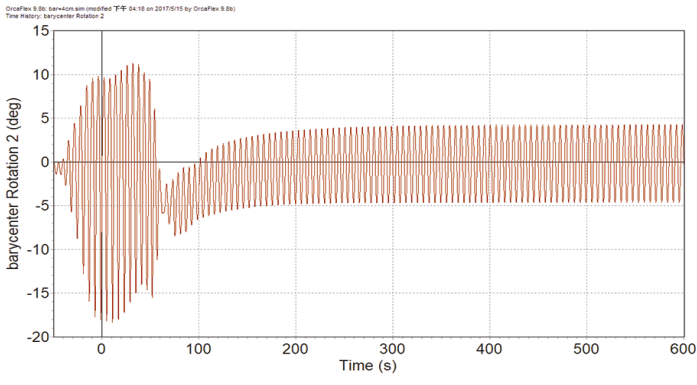

(c) $T=6 \mathrm{sec}$

Fig. 10. Pitch motion of system with iron chain of $d=0.04 \mathrm{~m}$

The results for $d=0.05 \mathrm{~m}$ are shown in Fig. 11. The amplitudes of fluctuations for all cases are reduced. However, at $T=6 \mathrm{sec}$, despite the fact that the pitching is small, it still can result in mooring line load fluctuations and lead to fatigue problems in long-term operations.

It should be mentioned that the reduction of pitching fluctuations for a chain with larger nominal diameter can be possibly attributed to the fact that the turbine system is located at a deeper position, where the water particle motion due to waves is smaller. Nevertheless, the results do show that the waves have strong impact on the operation of an ocean current turbine. This influence at least refers to the energy harvesting efficiency and system fatigue in long-term operation.

\section{B. 619 Wire Rope with Wire Core}

Fig. 12 shows the pitch motion for $d=0.03 \mathrm{~m}$ and different wave periods. At $T=4 \mathrm{sec}$, the computation leads to a blow-up solution which indicates that the system is unstable. At $T=5 \mathrm{sec}$, the computation does not blow up, but the pitch fluctuation is very intensive and may not be acceptable in practical deployment and operation. The pitching fluctuation is much reduced at $T=6 \mathrm{sec}$.

Figs. 6 and 8 show that the system with iron chain of $d=0.05 \mathrm{~m}$ and that with wire core of $d=0.03 \mathrm{~m}$ operate at

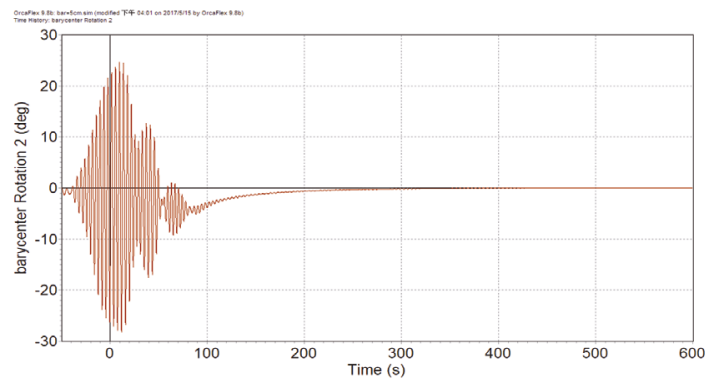

(a) $T=4 \mathrm{sec}$

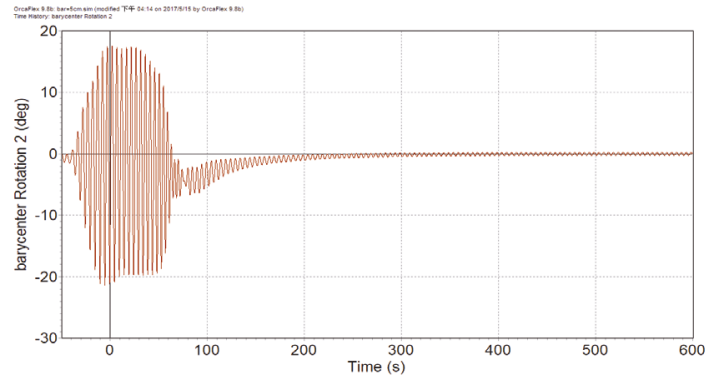

(b) $T=5 \mathrm{sec}$

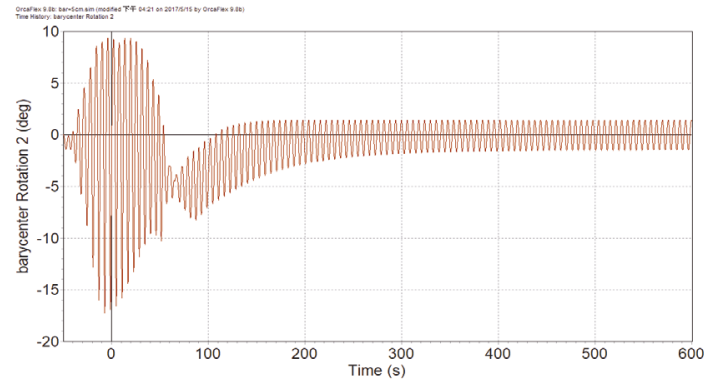

(c) $T=6 \mathrm{sec}$

Fig. 11. Pitch motion of system with iron chain of $d=0.05 \mathrm{~m}$

similar depth if no waves are present. However, under the wave action, the system responses shown in Figs. 11 and 12 are not similar. The response of the wire rope system is much worse, while the mooring with an iron chain appears to exhibit better performance for the present FKT system.

At $d=0.10 \mathrm{~m}$, the results shown in Fig. 13 are evidently much improved. The fluctuation of the system pitch motion is greatly reduced. Of course, for this condition, the wire rope is also much heavier, as can be observed in Fig. 8. In fact, the system operates at a depth close to the sea bed. The system does not fluctuate under normal operating conditions for $T=4 \mathrm{sec}$ and $5 \mathrm{sec}$. As for the case of $T=6 \mathrm{sec}$, only a small amplitude of fluctuation is observed.

\section{RESULTS: 3-AML SYSTEM WITH SURFACE WAVES}

In this section, the effect of 3-AML system on deployment dynamics in waves is considered. For different mooring lines, Figs. 14-16 show the amplitudes of stably oscillating pitching motion after deployment. It appears that there exists a resonant frequency (or period) in all situations, even though its value slightly varies for different mooring lines. The resonant 


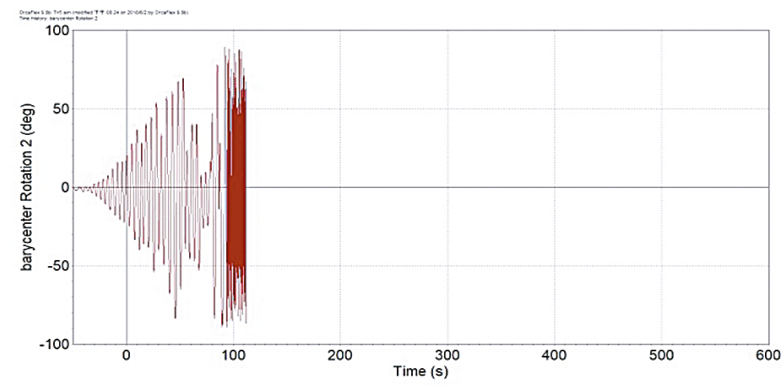

(a) $T=4 \mathrm{sec}$

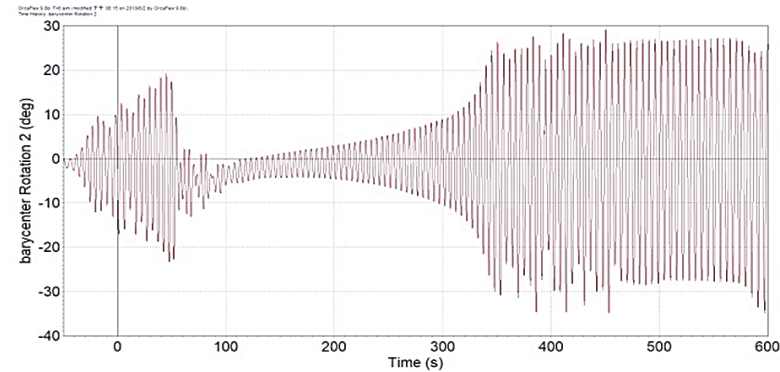

(b) $T=5 \mathrm{sec}$

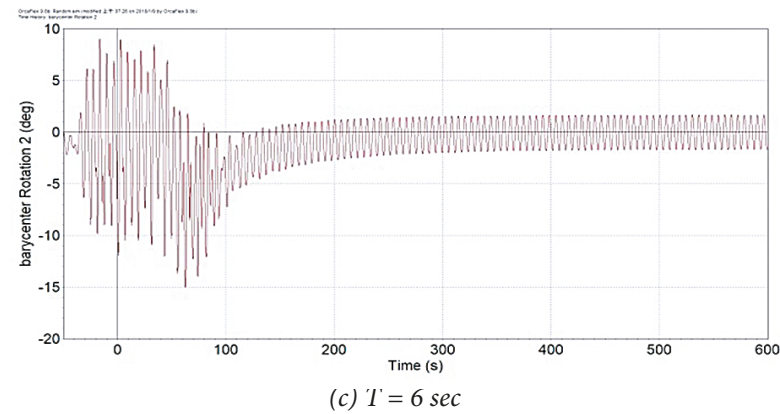

Fig. 12. Pitch motion of system with wire rope of $d=0.03 \mathrm{~m}$

frequency shown in Fig. 14 decreases with the increasing line diameter. For $d=0.03 \mathrm{~m}$, it is interesting to note the appearance of two peaks, which implies that the diameter in the 3-AML system has a significant effect on FKT system dynamics. In addition, large oscillation of pitch motion can be observed, with the period ranging from 4.83 to $7.85 \mathrm{sec}$. This is a wide range of wave period, for which the FKT system might not be able to work well. It implies that the 3-AML design is not a robust one, compared to the 2 -AML design as shown by $\mathrm{Wu}$ [23], if the polyester type of mooring line is employed and the line diameter is small. If the diameter is increased to $0.1 \mathrm{~m}$, the dynamic response is much improved, as shown in Fig. 14(b), and is similar to that of the 2-AML design.

The frequency responses of systems with iron-chain mooring lines are shown in Fig. 15. It shows that at small wave frequencies, $0.8-1.2 \mathrm{rad} / \mathrm{sec}$, (or wave periods of 5.23-7.85 sec), the FKT system responds periodically and more significantly to waves. Compared to the polyester lines, the fluctuations of the system with an iron chain are milder. The peak values appear at around $0.9-1.1 \mathrm{rad} / \mathrm{sec}$.

Fig. 16 shows the results for a wire rope of $d=0.1 \mathrm{~m}$ with wire core. The fluctuation amplitudes are much smaller than those in the previous two types of mooring lines. The peak appears at around $0.9 \mathrm{rad} / \mathrm{sec}$. However, for a small diameter,

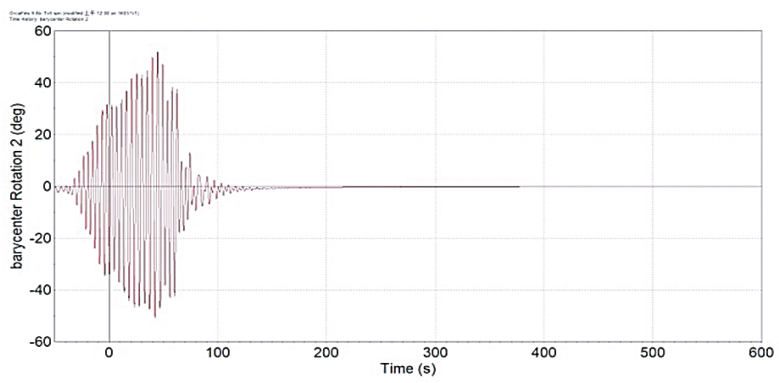

(a) $T=4 \mathrm{sec}$

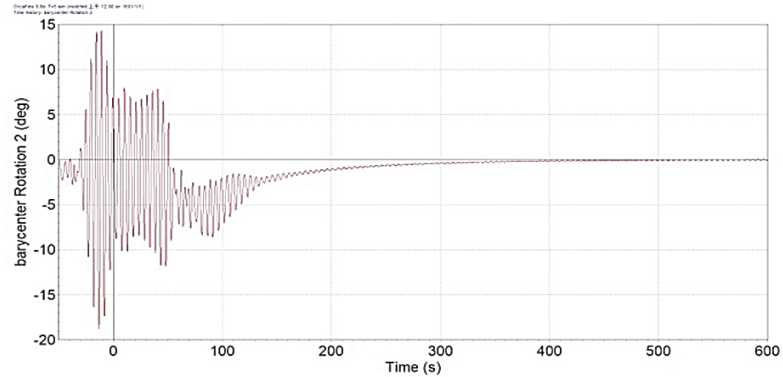

(b) $T=5 \mathrm{sec}$

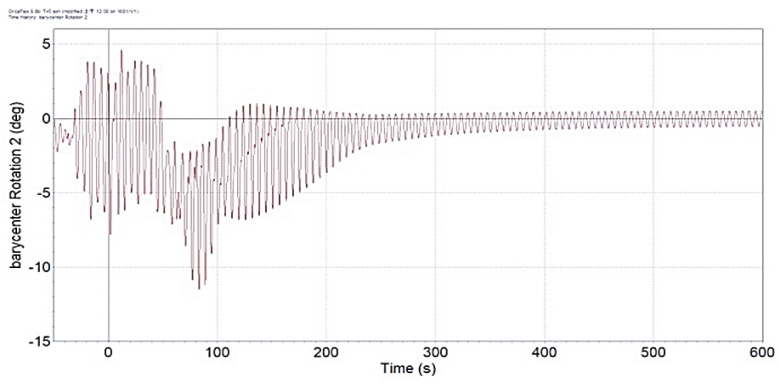

(c) $T=6 \mathrm{sec}$

Fig. 13. Pitch motion of system with wire rope of $d=0.1 \mathrm{~m}$

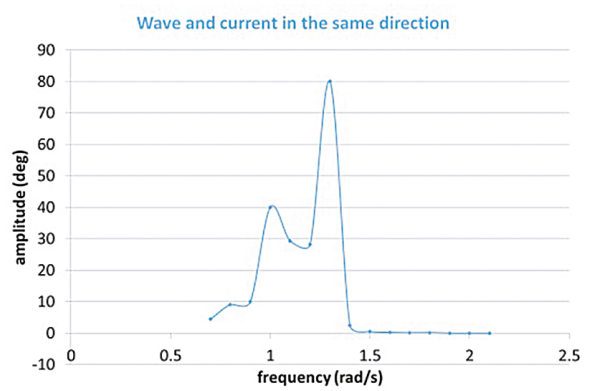

(a) $d=0.03 \mathrm{~m}$

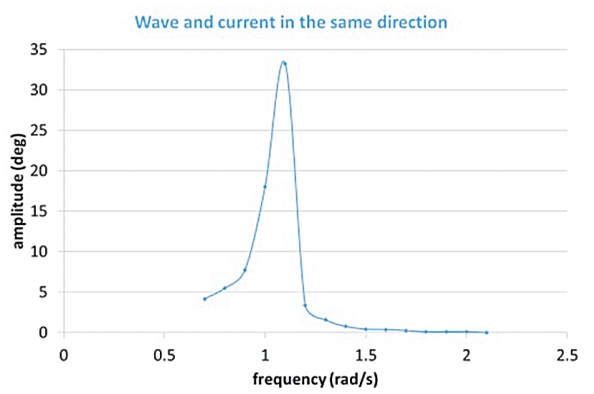

(b) $d=0.1 \mathrm{~m}$

Fig. 14. Amplitudes of pitching responses in frequency domain for 3-AML design with polyester lines 


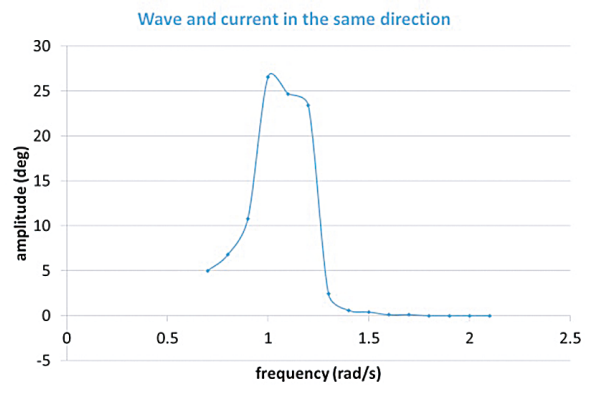

(a) $d=0.3 \mathrm{~m}$

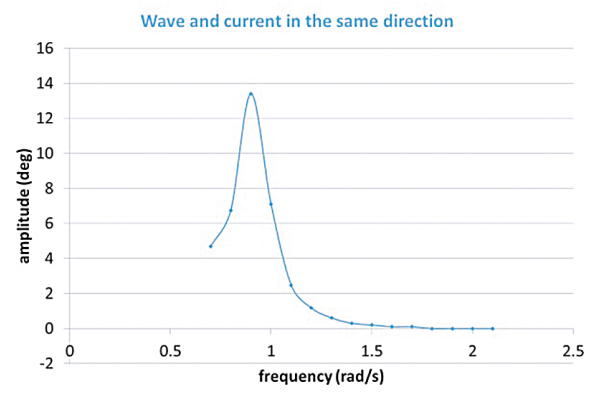

(b) $d=0.04 m$

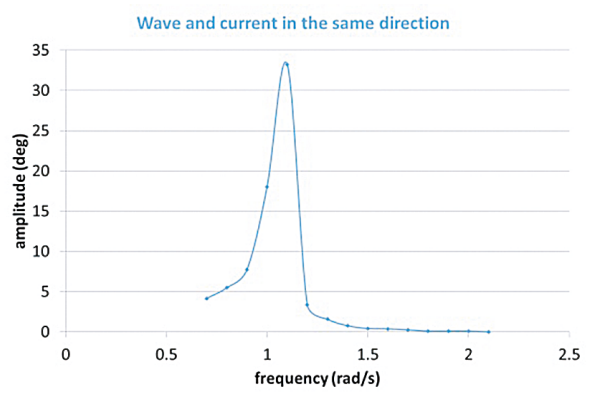

(c) $d=0.05 \mathrm{~m}$

Fig. 15. Amplitudes of pitching responses in frequency domain for 3-AML design with iron chains

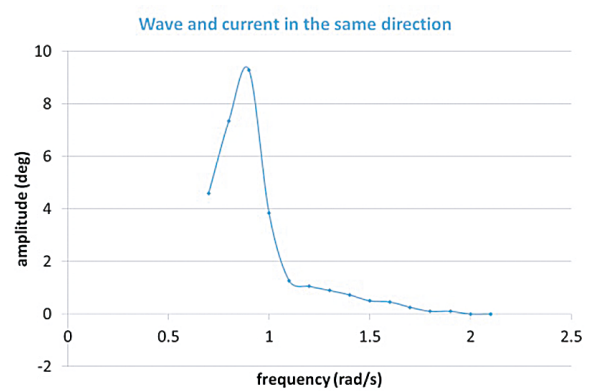

Fig. 16. Amplitudes of pitching responses in frequency domain for 3-AML design with wire rope of $d=0.1 \mathrm{~m}$ with wire core

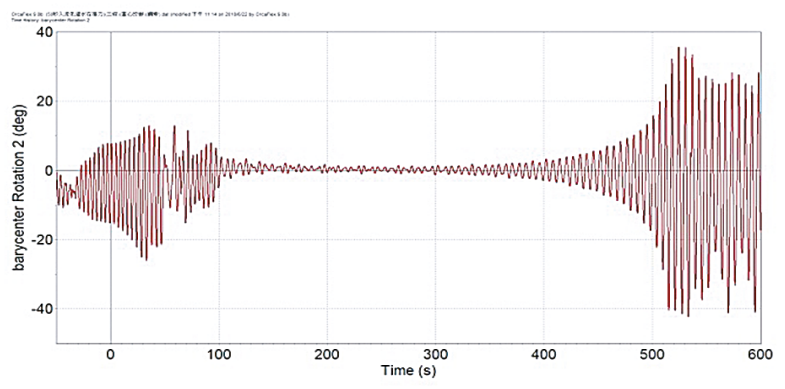

Fig. 17. Pitching responses for 3-AML design with wire rope of $d=0.03 \mathrm{~m}$ with wire core at wave period $T=4 \mathrm{sec}$ $d=0.03 \mathrm{~m}$, severe fluctuations appear in a wide frequency range, as shown in Fig. 17 given as an example. It appears that during the deployment process, the system gradually reaches its steady operating state, but the amplitude of the fluctuations is amplified.

To summarize the above computational results, the following observations can be made:

For the 3-AML system, the centre of gravity is closer to the mooring line connection point on the FKT system. The system appears to suffer large amplitude pitching motion more easily than the 2-AML system. The range of the wave period at which the pitching fluctuation becomes significant seems bigger than that of the 2-AML system with the same mooring lines in type and diameter. In addition, the diameter of any type of mooring line must be large enough to make the FKT system reach steady and stable operation. This implies that the mooring lines must exert relatively large restoring forces if the FKT system operates in the ocean current with waves on the free surface.

\section{CONCLUSIONS}

In the present study, the effect of mooring line type on the FKT system dynamics has been investigated numerically. Three different types of mooring lines were studied, which were: the polyester rope, the iron chain, and the wire rope. Two types of auxiliary mooring systems were investigated with different centres of gravity for the FKT system to make it horizontal under normal operating conditions.

The performed investigations have shown that without wave impact, the polyester rope can lead to system fluctuation or instability if its diameter is not sufficiently large. The performance of the system with iron chains and wire ropes is much improved. The system fluctuation in deployment can be related to the linear mass density of the mooring line. If the linear mass density is larger than some critical value, the system can exhibit good steadiness under normal operating conditions.

With wave impact, it has been found that, for the 2-AML system, the iron chain can have better performance than the wire rope in the sense that the system fluctuation is much smaller under normal operating conditions. Consequently, it is considered the best choice from among the three examined types of mooring lines for the present floating Kuroshio turbine system with Y-shape mooring line system. However, for the 3-AML design, the wire rope with wire core seems to perform better.

\section{ACKNOWLEDGMENT}

The study was made possible with the grant from Ministry of Science and Technology, the Republic of China, under the contract MOST 105-3113-E-002-019-CC2 and funding support from CSBC Corporation. 


\section{REFERENCES}

1. N.S. Diffenbaugh, D. Singh, and J.S. Mankin, Unprecedented climate events: Historical changes, aspirational targets, and national commitments, Sci. Advances, Vol. 4, eaao 3354, 2018.

2. H. Jeffrey, B. Jay, and M. Winskel, Accelerating the development of marine energy: Exploring the prospects, benefits and challenges, Technol. Forecast. Soc. Change, Vol. 80, pp. 1306-1316, 2013.

3. J. Van Zwieten, F.R. Driscoll, A. Leonessa, and G. Deane, "Design of a prototype ocean current turbine---Part I: mathematical modeling and dynamics simulation, Ocean Eng., Vol. 33, pp. 1485-1521, 2006.

4. F. Chen, The Kuroshio Power Plant, Switzerland: Springer, 2013.

5. IHI Corporation, Power generation using the Kuroshio Current, IHI Eng. Review, Vol. 46, pp. 2-5, 2014.

6. J.-Y. Bai, Ocean current power generation project, Workshop on Development of Marine Mechanical Energy Industry in Taiwan, Keelung, Taiwan, 2012 (in Chinese).

7. A. Røkke and R. Nilssen, Marine current turbines and generator preference: A technology review, Int. Conf. Renew. Energies Power Quality, Bilbao, Spain, 2013.

8. Y. Kyozuka, Tidal and ocean current power generation, J. Smart Processing, Vol. 3, pp. 137-145, 2014.

9. A.R. Cribbs, Model analysis of a mooring system for an ocean current turbine testing platform, M.S. thesis, Florida Atlantic University, Boca Raton, Florida, USA, Dec. 2010.

10. A.R. Cribbs and J.H. Van Zwieten, "Global numerical analysis of a moored ocean current turbine testing platform," Oceans, Seattle, OR, USA, 2010.

11. M. Shibata, K. Takeda, and K. Takgai, Mooring and power cable system for current-turbine, Oceans, San Diego, CA, USA, 2013.

12. K. Takagi, T. Waseda, S. Nagaya, Y. Niizeki, and Y. Oda, Development of a floating current turbine, Oceans, Hampton Roads, VA, USA, 2012.

13. Y.-H. Rho, C.-H. Jo, and D.-Y. Kim, Optimization of mooring system for multi-arrayed tidal turbines in a strong current area, Proc. ASME 33rd Int. Conf. Ocean, Offshore and Arctic Eng., San Francisco, CA, USA, 2014.

14. C.C. Tsao and A.H. Feng, Motion Model and Speed Control of the Cross-Stream Active Mooring System for Tracking
Short-Term Meandering to Maximize Ocean Current Power Generation, J. Mech., 1-15, 2017.

15. K. Shirasawa, J. Minami, and T. Shintake, Scale-model experiments for the surface wave influence on a submerged floating ocean-current turbine, Energies, Vol. 10, 702, 2017.

16. J.-T. Wu, J.-H. Chen, C.-Y. Hsin, and F.-C. Chiu, A computational study on system dynamics of an ocean current turbine, J. Hydrodyn., accepted, 2018.

17. A.R. Cribbs, G.R. Karrsten, J.T. Shelton, R.S. Nicoll, and W.P. Stewart, Mooring system considerations for renewable energy standards, Offshore Technology Conf., Houston, TX, USA, 2017.

18. A.E.D. Bowie, Flexible moorings for tidal current turbines, M.S. thesis, University of Strathclyde, Glasgow, UK, Sep. 2012.

19. C.H. Jo, D.Y. Kim, B.K. Cho, and M.J. Kim, Mooring analysis of duct-type tidal current power system in shallow water, Int. J. Geol. Environ. Eng., Vol. 10, pp. 577-582, 2016.

20. D.W. Atkins, The CFD assisted design and experimental testing of a wingsail with high lift devices, Ph.D. dissertation, University of Salford, Salford, UK, 1996.

21. H.Y. Lo, Dynamic analysis of current turbine system, M.S. thesis, National Taiwan Ocean University, Keelung, Taiwan, 2017 (in Chinese).

22. OrcaFlex Manual, Ver. 9.5a, Orcina Ltd., Cumbria, UK, 2011.

23. J.-T. Wu, J.-H. Chen, C.-Y. Hsin, and F.-C. Chiu, A computational study on system dynamics of an ocean current turbine, J. Hydrodyn., Vol. 30, pp. 395-402, 2018. 


\section{CONTACT WITH THE AUTHOR}

\section{Jiahn-Horng Chen}

jhchen202@gmail.com

National Taiwan Ocean University

2 Pei-ning Road, 20224 Keelung

TAIWAN 